\title{
Utility of FNAC as a Diagnostic Role in Lymphadenopathy Cases of Different Age Groups
}

\author{
Mahendra Singh ${ }^{1}$, Jaivijay Tiwari ${ }^{2 *}$ \\ ${ }^{1}$ Prof. \& Head, Department of Pathology, GSVM Medical College, Kanpur, India \\ 2Junior Resident III, Department of Pathology, GSVM Medical College, Kanpur, India
}

*Address for Correspondence: Dr. Jaivijay Tiwari, Junior Resident III, Department of Pathology, GSVM Medical College, Kanpur, U.P, India

E-mail: Jaivijay9415@gmail.com

Received: 12 Sep 2018/ Revised: 27 Oct 2019/ Accepted: 04 Nov 2019

\begin{abstract}
Background: Fine-needle aspiration cytology (FNAC) is a simple diagnostic tool to diagnose causes of lymphadenopathy. The cytologic patterns of lymph node fine needle aspirations (FNAs) show signs of a wide variation in different diseases. In the present study, we study the cytologic patterns of lymph node sequence of different age groups.

Methods: The present study was conducted in the Department of Pathology, GSVM Medical College, Kanpur. The total number of cases 1681 with lymphadenopathy was taken for this study. Routine investigations, which included complete blood counts, biochemical tests, X-Ray chest (PA View), Ultrasound/ CT scan (If indicated). FNAC was done and the slides were stained with Haematoxylin and Eosin stain, Giemsa stain and Ziehl-Neelsen stain (if indicated).

Results: In the present study, the commonest site of involvement was the cervical lymph node 1196 (71.15\%). Overall benign lesions were 1575 (93.69\%) and malignant lesions 106 (6.31\%). In benign lesions, Tubercular lymphadenitis was the most frequently encountered lesion 934 (55.56\%) followed by reactive hyperplasia 310 (18.44\%). FNAC is a simple procedure and no hospitalization or anaesthesia is required.

Conclusion: FNAC is a safe, inexpensive repeatable and rapid procedure in which no anaesthesia is required. FNAC is useful as an outdoor diagnostic procedure because of early diagnosis in comparison to histopathological diagnosis.
\end{abstract}

Key-words: Cervical lymph node, FNAC, Lymphadenopathy, Metastatic, Reactive Hyperplasia, Tuberculous Lymphadenitis

\section{INTRODUCTION}

Lymph nodes play a major role in the host defense system as not only cleans and filter lymph but also produce lymphocytes and antibodies. The term lymphadenopathy refers to lymph nodes, which are abnormal in size, number or firmness ${ }^{[1]}$. Depending on the locations draining particulars topographic regions, they are grouped as cervical, axillary, Supra-clavicular, auricular, inguinal, sub-mental lymph nodes and so on ${ }^{[2]}$. The etiology of lymphadenopathy varies from infectious, autoimmune disease, metabolic disease, malignancies etc.
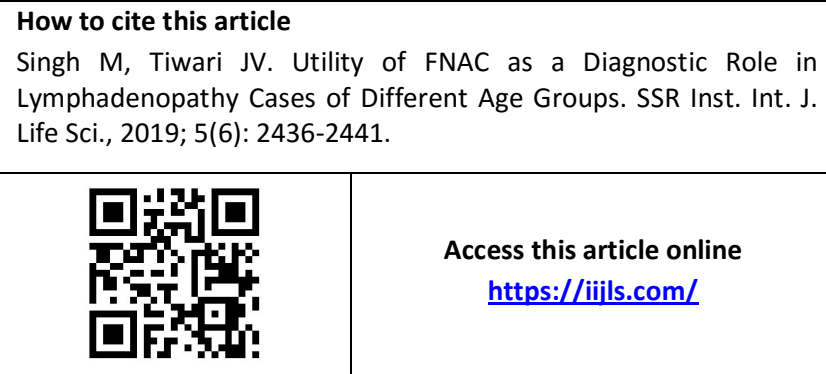

Access this article online https://iijls.com/
Enlarged lymph nodes are easily approachable for fine needle aspiration and hence FNAC is a simple and important diagnostic tool for lymphadenopathy. Lymphadenopathy is most commonly seen in extrapulmonary tuberculosis and tuberculous lymphadenitis is the frequent cause of peripheral lymphadenopathy ${ }^{[3]}$. Rapid Strides in the technical advancement of FNAC has made it very easier to diagnose most of the lesions of lymph nodes has reduced otherwise time-consuming and invasive open biopsy of lymph nodes. FNAC is a simple procedure, which is a safe rapid and inexpensive and relatively less invasive method that could be carried out as an outdoor procedure without anaesthesia for establishing the diagnosis of pathological lesions occurring in lymph nodes on the exposed, easily accessible regions of the body ${ }^{[4,5]}$. This study was undertaken with the aim of highlighting the pattern of lymphadenopathy on FNAC. 
cross ef DOI:10.21276/SSR-IIJLS.2019.5.6.4

\section{MATERIALS AND METHODS}

Study duration- Duration of study was from January 2018 to September 2019. The total number of cases included 1681 of lymphadenopathy in the Department of Pathology in collaboration with Department of Medicine, ENT, Paediatrics, Surgery, TB chest and Oncology, G. S. V. M. Medical College, Kanpur and associated hospital Kanpur, India.

The study group includes patients of different age groups suffering from various diseases attending OPD, referred for the FNAC of enlarged lymph nodes in the department of pathology. The patient was explained about the procedure and informed consent was taken. The $20 \mathrm{ml}$ disposable syringe was attached to a 22 gauge needle; the lymph node was palpated, localized and fixed between two fingers. The overlying skin was swabbed by rectified spirit. The needle was inserted into the palpable lymph node. A vacuum was created by withdrawing piston of the syringe. The vacuum was maintained while repeated runs in different directions in the palpable lymph node. The needle along with syringe was withdrawn together. The aspirated material was squirted onto the clean glass slides and smears were prepared by pulling apart two slides. The slide was fixed in fixative containing 95\% alcohol and diethyl ether and stained with two methods viz. Haematoxylin \& Eosin stain and Giemsa stain. If necessary, then Smear was also stained by ZN stain.

\section{RESULTS}

In the present study, FNAC was performed on 1681 patients. Table 1 shows that 751 patients were male and 930 patients were female. The proportion of male to the female patient was $1: 1.24$. The maximum numbers of cases were detected in the age range of $11-20$ years $(28.37 \%)$, followed by the age group 21-30 years (24.98\%). The total number of lymphadenopathy cases detected in the age range of $0-10$ years was $19.69 \%$.

Table 1: Distribution of cases according to age group and sex incidence

\begin{tabular}{|c|c|c|c|}
\hline \multirow{2}{*}{$\begin{array}{l}\text { Age Group } \\
\text { (years) }\end{array}$} & \multicolumn{2}{|c|}{ Sex } & \multirow{2}{*}{$\begin{array}{c}\text { Percentage } \\
\text { (\%) }\end{array}$} \\
\hline & Male & Female & \\
\hline $0-10$ & 200 & 131 & 19.69 \\
\hline $11-20$ & 198 & 279 & 28.37 \\
\hline $21-30$ & 114 & 306 & 24.98 \\
\hline $31-40$ & 77 & 106 & 10.89 \\
\hline $41-50$ & 67 & 57 & 7.38 \\
\hline
\end{tabular}

$\begin{array}{cccc}51-60 & 51 & 38 & 5.29 \\ 61-70 & 37 & 10 & 2.80 \\ 71-80 & 7 & 2 & 0.54 \\ 81-90 & 0 & 1 & 0.06 \\ \text { Total } & 751 & 930 & 100\end{array}$

In this study, the most common site was the cervical lymph node $(71.15 \%)$, followed by sub-mandibular (7.73\%), and axillary (5.77\%) lymph node. In cervical lymph nodes, most of the cases had posterior cervical lymphadenopathy (65.8\%) followed by upper anterior cervical lymphadenopathy (5.35\%) (Table 2 ).

Table2: Anatomical Distribution of Enlarged Lymph Nodes

\begin{tabular}{ccc}
\hline Site & Total & Percentage (\%) \\
\hline Cervical lymph & 1196 & 71.15 \\
node & & \\
Sub-mandibular & 130 & 7.73 \\
Axillary & 97 & 5.77 \\
Supra-clavicular & 97 & 5.77 \\
Inguinal & 67 & 3.99 \\
Sub-mental & 61 & 3.63 \\
Auricular & 31 & 1.84 \\
Mesenteric & 1 & 0.06 \\
Pelvic & 1 & 0.06 \\
Total & 1681 & 100 \\
\hline
\end{tabular}

In this study, 751 patients were male and 930 patients were female. Reactive hyperplasia of lymph node more commonly affect male 178 cases (57.42\%) as compared to female 132 cases (42.58\%). Male to female ratio was 1.35: 1 . Tubercular cases more commonly affect female 425 cases (65.89\%) as compared to male 220 cases (34.11\%). Male to female ratio was 1: 1.93 (Table 3).

Table 4 shows the reactive hyperplasia of lymph node more commonly seen in the age range of 0-10 yrs accounting to $50.79 \%$ of cases, followed by $11-20$ yrs age range of accounting to $30.60 \%$ cases. Tubercular cases most commonly detected in the age range of 2130 accounting to 220 (34.11\%) cases followed by in the age range of 11-20 yrs accounting to 191 (29.61\%) cases. Out of 99 cases of metastatic carcinoma, 36 cases (36.36\%) was in the age range of 51-60 yrs, followed by 23 cases (23.23\%) of age range of $61-70$ yrs, followed by 23 cases (23.23\%) age range of 61-70 yrs and 21 cases (21.21\%) age range of $41-50$ yrs. 
Table 3: Gender wise distribution of patients according to cytological diagnosis

\begin{tabular}{cccc}
\hline FNAC Diagnosis & \multicolumn{2}{c}{ Sex } & \multirow{2}{*}{ Total } \\
\cline { 2 - 3 } RHLN & Male & Female & \\
CL & 178 & 132 & 310 \\
TB Abscess & 78 & 94 & 172 \\
TBLN with Extensive caseation & 97 & 156 & 253 \\
TB LN & 22 & 48 & 70 \\
CGL & 101 & 221 & 322 \\
CGL with strong possibility of TB & 54 & 53 & 107 \\
Necrotizing Lymphadenitis & 81 & 158 & 239 \\
Organized Abscess & 4 & 5 & 9 \\
RHLN with sinus histocytosis & 22 & 28 & 50 \\
Metastatic carcinoma & 12 & 7 & 19 \\
Atypical hyperplasia of LN & 5 & 2 & 7 \\
Total & 80 & 19 & 99 \\
Necrotizing Lymphadenitis with strong possibility of TB & 17 & 7 & 24 \\
\hline
\end{tabular}

L= Chroinic lymphadenitis, CGL= Chronic granulomatous lymphadenitis, TBLN= Tubercular lymphadenitis, RHLN= Reactive Hyperplasia of lymph node

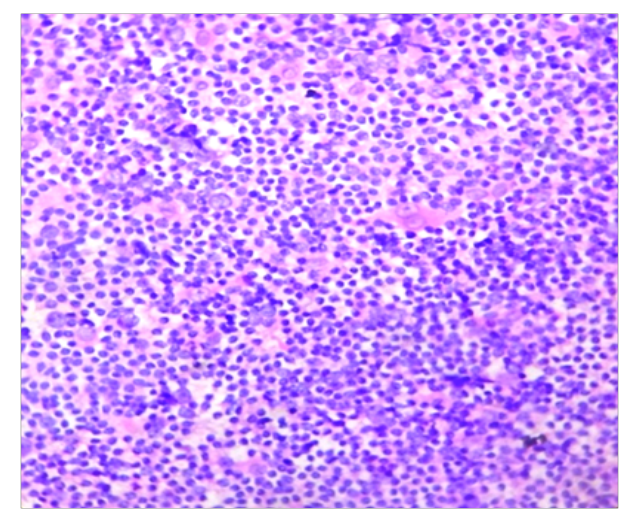

Fig. 1A: Reactive hyperplasia of lymph node ( 40x H\&E)

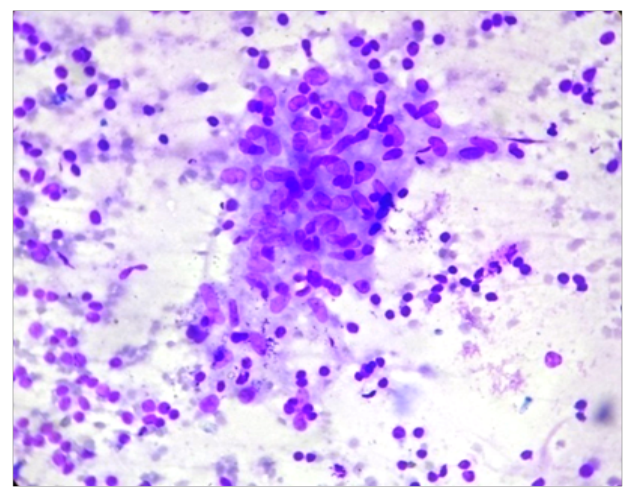

Fig. 1C: Chronic granulomatous lesion with possibility of tubercular lymphadenitis (40x Giemsa )

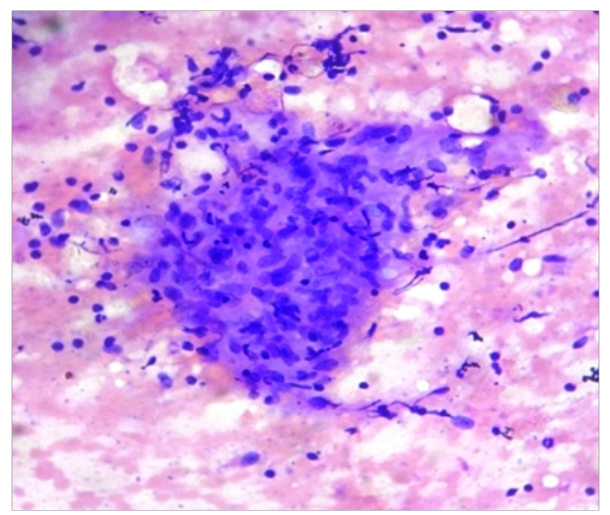

Fig. 1B: Photomicrograph of aspiration smear of tubercular lymphadenitis (40x $H \& E$ )

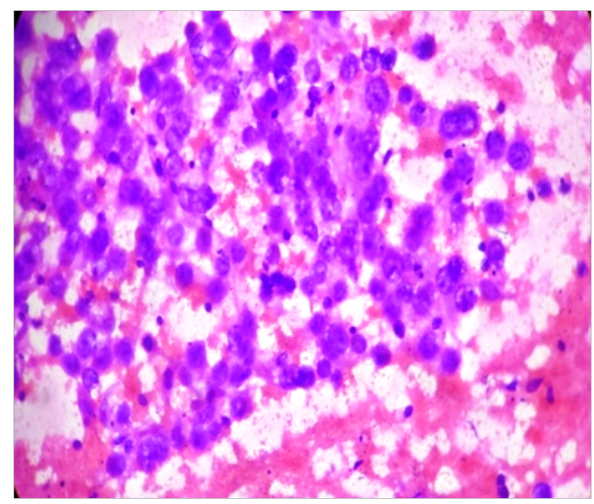

Fig. 1D: Poorly Differentiated squamous cell carcinoma with cystic changes with a strong possibility of adenosquamous carcinoma (40x Giemsa) 
Table 4: Age-wise distribution of patients according to cytological diagnosis

\begin{tabular}{|c|c|c|c|c|c|c|c|c|c|}
\hline \multirow[b]{2}{*}{ FNAC Diagnosis } & \multicolumn{9}{|c|}{ Age group (Years) } \\
\hline & $0-10$ & $11-20$ & $21-30$ & $31-40$ & $41-50$ & $51-60$ & 61-70 & $71-80$ & $81-90$ \\
\hline RHLN (with sinus histiocytosis) & 161 & 97 & 34 & 11 & 7 & 4 & 2 & 1 & 0 \\
\hline $\mathrm{CL}$ & 59 & 48 & 35 & 9 & 13 & 6 & 1 & 1 & 0 \\
\hline TB Abscess & 30 & 59 & 88 & 38 & 21 & 13 & 2 & 2 & 0 \\
\hline TB LN & 25 & 105 & 108 & 50 & 24 & 8 & 1 & 0 & 1 \\
\hline TBLN with Extensive caseation & 5 & 27 & 24 & 10 & 3 & 0 & 1 & 0 & 0 \\
\hline CGL & 13 & 45 & 30 & 10 & 3 & 4 & 2 & 0 & 0 \\
\hline CGL with strong Possibility of TB & 21 & 75 & 77 & 29 & 19 & 9 & 9 & 0 & 0 \\
\hline Necrotizing Lymphadenitis & 3 & 0 & 2 & 0 & 3 & 0 & 1 & 0 & 0 \\
\hline Necrotizing Lymphadenitis with & & & & & & & & & \\
\hline $\begin{array}{c}\text { Strong } \\
\text { Possibility of TB }\end{array}$ & 3 & 15 & 13 & 9 & 4 & 4 & 2 & 0 & 0 \\
\hline Atypical hyperplasia of LN & 8 & 4 & 3 & 2 & 3 & 3 & 1 & 0 & 0 \\
\hline Organized Abscess & 3 & 2 & 3 & 3 & 3 & 2 & 2 & 1 & 0 \\
\hline Metastatic carcinoma & 0 & 0 & 3 & 12 & 21 & 36 & 23 & 4 & 0 \\
\hline Total & 331 & 477 & 420 & 183 & 124 & 89 & 47 & 9 & 1 \\
\hline
\end{tabular}

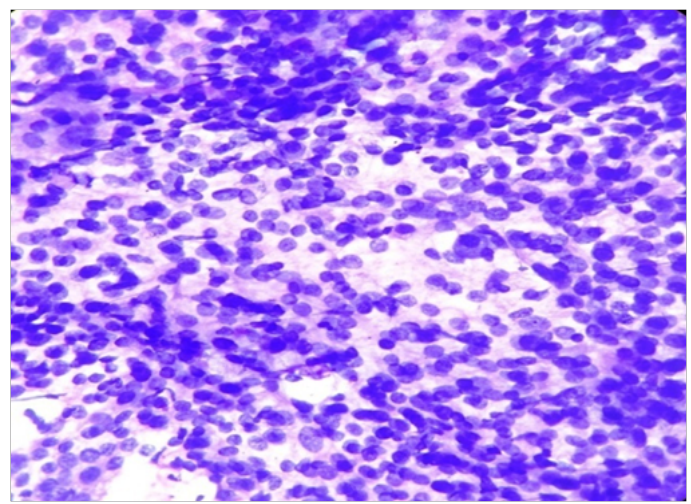

Fig. 2: Poorly Differentiated Squamous cell carcinoma (40X H\&E)

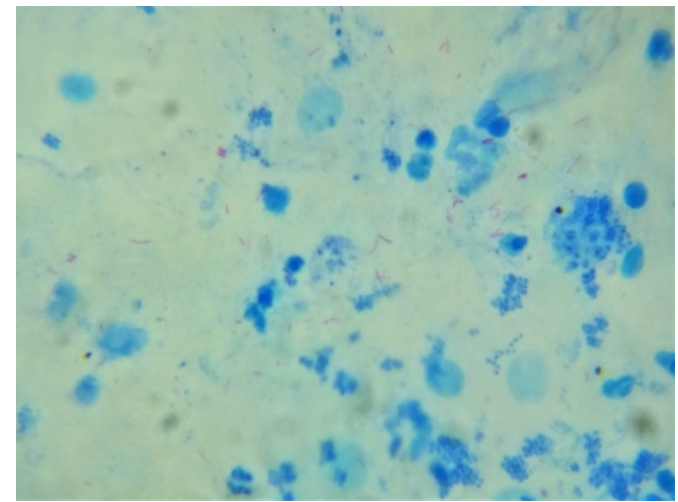

Fig. 3: Photomicrograph of Ziehl Neelsen Staining of Aspiration smear of tubercular abscess $(100 \times \mathrm{ZN})$
Out of 1681 cases of lymphadenopathy, 1575 cases (93.69\%) of benign pathology and 106 cases $(6.31 \%)$ of malignant pathology found. In out of 1575 benign cases, 664 cases $(42.16 \%)$ were of male and 911 cases were (57.84\%) of female and male to female proportion was 1 :

\subsection{7 .}

Table 5: Distribution of benign and malignant cases according to sex

\begin{tabular}{ccccc}
\hline $\begin{array}{l}\text { Nature of } \\
\text { Lesion }\end{array}$ & Percentage (\%) & Male (\%) & Female (\%) & Ratio (M: F) \\
\hline Benign & 93.69 & $664(42.16)$ & $911(57.84)$ & $1: 1.37$ \\
Malignant & 6.31 & $87(82.08)$ & $19(17.92)$ & $4.58: 1$ \\
Total & & 751 & 930 & \\
\hline
\end{tabular}




\section{DISCUSSION}

Enlarged lymph nodes are accessible for FNAC to diagnose primary or secondary malignancies and benign lesion. Cases of lymphadenopathy are most commonly seen in $11-20$ yrs age group and its range was $28.37 \%$. This finding was correlated by Agarwal et al. ${ }^{[6]}$ and also a correlation with study given by Arun et al. ${ }^{[7]}$ Nirmal et al. ${ }^{[8]}$ and Patro et al. ${ }^{[9]}$. The proportion of male to female patients in our observation was found to be $1: 1.24$. This finding is correlated to past study that given by Nirmal et al. ${ }^{[8]}$; Patro et al. ${ }^{[9]}$; and Mane et al. ${ }^{[10]}$. Our study correlates lymphadenopathy was seen in most commonly in the cervical region $(71.15 \%)$ and other similar studies lymphadenopathy was most commonly seen in neck region i.e. $93.73 \%{ }^{[11]}$ and $72.5 \%$ cases of cervical in which FNAC was performed given by Ikram et al. ${ }^{[12]}$. The cervical lymph node was the most frequently affected group of lymph nodes accounting to $74.24 \%$ similar observations also given by Patro et al. ${ }^{[9]}$; Farooq et al. ${ }^{[13]}$ and Nur et al. ${ }^{[14]}$.

In the present study, $93.69 \%$ of cases were of inflammatory lesion of the lymph node. Out of inflammatory lesions, the most common lesion was tubercular lymphadenopathy accounting to $55.5 \%$ cases, reactive hyperplasia of lymph node accounts for $18.86 \%$ cases. Most common causes of lymphadenopathy were found to be tuberculous lymphadenitis with $32.12 \%$ cases given by Patro et al. ${ }^{[9]}$. Florence et al. ${ }^{[15]}$ stated that $35.9 \%$ case tubercular lymphadenitis was found, which is most frequent than other cases. In our study metastasis is most commonly seen in the cervical lymph node, which is similar to results of other studies given by Nirmal et al. ${ }^{[8]}$ and Florence et al. ${ }^{[15]}$.

In our study, males were most commonly affected by reactive hyperplasia of lymph node; proportion of male to female was 1.35: 1. Whereas, females are most commonly affected by tubercular lymphadenopathy; the proportion of male to female was 1: 1.93. Our study was shown similar result by some previously published studies by Farooq et al. ${ }^{[13]}$; Nur et al. ${ }^{[14]}$; Badge et al. ${ }^{[16]}$ and Bhatta et al. [17]. In our study, tubercular lymphadenopathy cases are most commonly seen in the age range of $21-30$ years accounting $34.11 \%$ followed by the age range of $11-20$ years accounting to $29.61 \%$, cases. Correlate to the past studies that observed by some previous studies, given by Agarwal et al. ${ }^{[8]}$; Nur et al. ${ }^{[14]}$; Badge et al. ${ }^{[16]}$ and Mainali et al. ${ }^{[18]}$.
In our study metastatic carcinoma was most commonly seen in the age group i.e. $51-60$ yrs (36.36\%) followed by 61-70 yrs age range (23.23\%). Khajuria et al. ${ }^{[5]}$ found that after $4^{\text {th }}$ decades overall percentage of metastatic carcinoma was $88 \%$. Agarwal et al. ${ }^{[6]}$; Mane et al. ${ }^{[10]}$ and Nikethan et al. ${ }^{[19]}$ stated that metastasis was seen in the middle and elderly age group. In our observations, $16.27 \%$ of cases of tubercular lymphadenitis were AFB positive on Z-N staining but Badge et al. ${ }^{[16]}$ stated that AFB positive in $28.47 \%$ cases of tubercular lymphadenitis with the closed result. Overall AFB positive $32.4 \%$ of cases in tubercular lymphadenitis observed by Bhatta et al. ${ }^{[17]}$.

\section{CONCLUSIONS}

Our study show cased, the usefulness of FNAC in reaching a prompt diagnosis in patients presenting with lymphadenopathy and also put light on etiology and pattern of lymphadenopathy. FNAC is a safe inexpensive rapid procedure in which no anaesthesia required. FNAC is useful as an outdoor diagnostic procedure because of early diagnosis in comparison to histopathological diagnosis.

Fine Needle Aspiration Cytology finding should be correlated with the histopathological finding.

\section{ACKNOWLEDGMENTS}

All authors are very thankful to the Department of Pathology, G. S. V. M. Medical College Kanpur, India for help in writing the paper.

\section{CONTRIBUTION OF AUTHORS}

Research concept- Prof. Mahendra Singh, Dr. Jaivijay Tiwari

Research design- Dr. Jaivijay Tiwari

Supervision- Prof. Mahendra Singh

Materials- Dr. Jaivijay Tiwari

Data collection- Dr. Jaivijay Tiwari

Data analysis and Interpretation- Prof. Mahendra Singh, Dr. Jaivijay Tiwari

Literature search- Dr. Jaivijay Tiwari

Writing article- Dr. Jaivijay Tiwari

Critical review- Prof. Mahendra Singh

Article editing- Dr. Jaivijay Tiwari

Final approval- Prof. Mahendra Singh

\section{REFERENCES}

[1] Westhoff TH, Loddenkemper C, Horl MP, et al. Dermatopathic lymphadenopathy: a differential 
diagnosis of enlarged lymph nodes in uremic pruritus. Clin. Nephrol., 2006; 66: 472-75. doi: 10.5414/cnp66472.

[2] Vimal S, Dharwadkar A, Chandanwale SS, Vishwanathan V, Kumar H. Cytomorphological study of lymph node lesion: A study of 187 cases. Med. J. DY. Patil Univ., 2016; 9: 43-50

[3] World Health Organization. Global Tuberculosis Report, 2015; 2015-18.

[4] Bhide S, Katre RY, Joshi SR. Cytological Evaluation of Fine Needle Aspiration cytology in Lymph Node lesion. J. Med. Sci. Clin. Res., 2017; 5(8): 26869-76. doi: https://dx.doi.org/10.18535/jmscr/v5i8.147.

[5] Khajuria R, Goswami KC, Singh K, Dubey VK. Pattern of lymphadenopathy on fine needle aspiration cytology in Jammu. JK Sci., 2006; 8(3): 157-59.

[6] Agarwal D, Bansal P, Rani P, Sharma S, Chawla S, et al. Evaluation of etiology of lymphadenopathy in different age groups using fine needle Aspiration Cytology: A retrospective study. Internet J. Pathol., 2009; 10(2): 01-06.

[7] More SA, Bhalara RV, Shah PM, Talwelkar SR, Dhruva GA. FNAC of cervical Lymph Nodes. Int. J. World Res., 2010; 2(1): 26-32.

[8] Nirmal AK, Nirmal K, Jha J, Kumar S. Role of fine needle aspiration cytology in assessment of cervical lymphadenopathy in variable age groups: A retrospective study. Int. J. Med. Res. Health Sci., 2016; 5(11): 306-10.

[9] Patro P, Lad P, Hoogar MB, Dhar R, Sahu S, et al. Spectrum of lesions in Lymph Nodes-A cytological, Study. Int. J. Health Sci. Res., 2018; 8(11): 75-81.

[10]Mane P, Namey R. Utility of FNAC in Lymphadenopathy. Int. J. Med. Health Res., 2017; 3(5): 10-13.
[11] Rani R, Bhargava R, Verma N, Prakash C, Sharma S, et al. A study of pattern of lymphadenopathy on Fine Needle Aspiration Cytology in and around Meerut, U.P. (India). Int. J. Pathol., 2014; 16(1): 1-7.

[12] Ikram A, Mahmood S. Evaluation of fine needle aspiration cytology among lymphadenopathy patients in Ambedkarnagar, Uttar Pradesh, India. Int. J. Adv. Med., 2017; 4(2): 519-22.

[13]Farooq S, Amain J, Singh K, Jahan S. Evaluation of lymphadenopathy using FNAC as a Diagnostic Tool. Int. J. Contemporary Med. Res., 2018; 5(1) 78-83.

[14]Nur TE, Shirin A, Saha MM. Diagnostic Accuracy of Fine Needle Aspiration cytology in Diagnosis of Tuberculous lymphadenitis. J. Enam. Med. Coll., 2019; 9(1): 30-33.

[15]Tamilselvi V, Peranantham S. Diagnostic role of FNAC in metastatic lymphadenopathies-our institutional experience. Med. pulse. Int. J. Pathol., 2018; 7(1): 0911.

[16]Badge SA, Anjalee G, Azad OK, Meshram AT. Study of fine needle aspiration cytology of lymph node in rural area of Bastar District, Chhattisgarh. Med. J. Dr. D.Y. Patil Univ., 2017; 10(2): 143-48.

[17]Sushama B, Singh S, Sangita RC. Diagnostic Value of Fine Needle Aspiration cytology in the assessment of cervical lymphadenopathy. Official J. NMC. Birgung, Nepal, 2018; 3(1): 36-40.

[18]Mainali N, Suwal RB. Pattern of Iymphadenopthy on fine needle aspiration cytology in eastern Nepal. J. Path. Nepal, 2015; 5: 814-16.

[19]Nikethan B, Neethu GV, Hiremath SS, Patil SB. Role of fine needle aspiration cytology in the evolution of the etiology of lymphadenopthy. Ind. J. Pathol. Oncol., 2016; 3(4): 548-51. 